3 Gardner MJ, Snee MP, Hall A, et al. Results of a case-control study of leukaemia and lymphoma among young people near Sellafield nuclear plant in west Cumbria. BMf 1990;300:423-9.

4 Breslow NE, Day NE. Statistical methods in cancer research (vol $I$ ). The analysis of case-control studies. Lyons: International Agency for Research on Cancer, 1980.

5 Anonymous. EGRET. Seattle: Statistics and Epidemiology Research Corporation, 1989

6 Heasman MA, Urquhart JD, Kemp IW, Black RJ. Childhood leukaemia in northern Scotland. Lancet 1986;i:266.

Heasman MA, Kemp IW, Urquhart JD, Black RJ. Leukaemia and lymphatic cancer in young people near nuclear installations. Lancet 1986; $1: 385$.

8 Heasman MA, Urquhart JD, Kemp IW, et al. Leukaemia in young persons in

Scotland: a study of its geographical distribution and relationship to nuclear installations. Health Bull 1987;45:147-51.

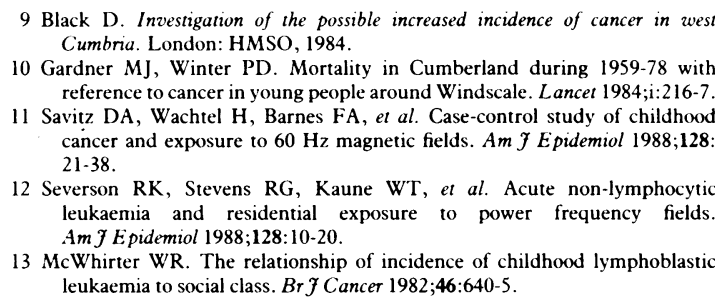

9 Black D. Investigation of the possible increased incidence of cancer in west Cumbria. London: HMSO, 1984.

10 Gardner MJ, Winter PD. Mortality in Cumberland during 1959-78 with reference to cancer in young people around Windscale. Lancet 1984;i:216-7.

11 Savitz DA, Wachtel H, Barnes FA, et al. Case-control study of childhood cancer and exposure to $60 \mathrm{~Hz}$ magnetic fields. Am $\mathcal{F}$ Epidemiol 1988;128: 21-38

12 Severson RK, Stevens RG, Kaune WT, et al. Acute non-lymphocytic leukaemia and residential exposure to power frequency fields. Am J Epidemiol 1988:128:10-20.

$13 \mathrm{McWhirter}$ WR. The relationship of incidence of childhood lymphoblastic leukaemia to social class. Br f Cancer 1982;46:640-5.

(Accepted 6 February 1991)
Departments of Neurology and Pathology, University of Glasgow

J W Gow, PHD, research

fellow in neuroimmunology

W H M Behan, MD, senior lecturer in pathology $\mathrm{PO}$ Behan, MD, professor of neurology

Regional Virus Laboratory and Scottish Serum Bank, Ruchill Hospital, Glasgow G B Clements, PHD, consultant in charge, regional virus laboratory

C Woodall, PHD, research fellow

M Riding, MSC, research assistant

Correspondence and requests for reprints to: Professor P O Behan, Department of Neurology, Institute of Neurological

Sciences, Southern General

Hospital, 1345 Govan Road, Glasgow G51 4TF.

BMF 1991;302:692-6

\title{
Enteroviral RNA sequences detected by polymerase chain reaction in muscle of patients with postviral fatigue syndrome
}

\author{
J W Gow, W M H Behan, G B Clements, C Woodall, M Riding, P O Behan
}

\begin{abstract}
Objective-To determine the presence of enteroviral sequences in muscle of patients with the postviral fatigue syndrome.

Design-Detection of sequences with the polymerase chain reaction in a well defined group of patients with the syndrome and controls over the same period.

Setting-Institute of Neurological Sciences, Glasgow.

Subjects -60 consecutive patients admitted to the institute with the postviral fatigue syndrome who had undergone extensive investigation to exclude other conditions. 41 controls from the same catchment area without evidence of fatigue, all undergoing routine surgery.
\end{abstract}

Main outcome measures-Routine investigations, serological screen for antibodies to a range of viruses, and presence of enteroviral RNA sequences in muscle biopsy specimens.

Results-15 (25\%) patients and $10(24.4 \%)$ controls had important serological findings. 12 patients had neutralising antibody titres of $\geqslant 256$ to coxsackieviruses B1-5 (six positive for enteroviral RNA sequences, six negative); three were positive for Epstein-Barr virus specific IgM (two positive, one negative). Six controls had similar neutralising antibody titres to coxsackieviruses (all negative); one was positive for Epstein-Barr virus specific IgM (negative); and three had titres of complement fixing antibody $\geqslant 256$ to cytomegalovirus-(all negative). Overall, significantly more patients than controls had enteroviral RNA sequences in muscle $(32 / 60$, $53 \% v 6 / 41,15 \%$; odds ratio $6.7,95 \%$ confidence interval $2 \cdot 4$ to $18 \cdot 2$ ). This was not correlated with duration of disease, patient and age, or to raised titres of antibodies to coxsackieviruses B1-5.

Conclusions-Persistent enteroviral infection of muscle may occur in some patients with postviral fatigue syndrome and may have an aetiological role.

\section{Introduction}

Patients with a protracted fatigue state after an acute, apparently viral infection (the postviral fatigue syndrome) may present to general practitioners, physicians, neurologists, or psychiatrists. ${ }^{1-3}$ The fatigue is accompanied by myalgia, and most patients also have psychiatric symptoms, particularly depression and disturbance of sleep. About one third complain of palpitations or unsteadiness, or both. Physical signs, however, are inconsistent or absent, and routine laboratory test results are normal. ${ }^{3}$
The features of this disorder suggest that the fatigue is caused by involvement of both muscle and the central nervous system. There is some direct evidence of muscle damage as membrane abnormalities are detectable on single fibre electromyography. ${ }^{4}$ In the few patients studied by magnetic resonance investigations unusually early intracellular acidosis out of proportion with the associated rise in high energy phosphates was reported on exercise. (D L Arnold et al, abstract, third annual meeting of the Society for Magnetic Resonance in Medicine, New York, 1984.) Muscle biopsy specimens may disclose moderate diffuse atrophy of type 2 fibres. ${ }^{6}$

Diagnosis and definition of this disease have been difficult, but we have now established a set of criteria, similar to those delineated in a recent working case definition, ${ }^{7}$ except that the disease is diagnosed only in relation to an acute onset after a feverish illness. The postviral fatigue syndrome has many synonyms - for example, myalgic encephalomyelitis ${ }^{1}$ and postviral epidemic neuromyasthenia ${ }^{2}$ - but we use the term postviral fatigue syndrome as this draws immediate attention to its two cardinal features.

The disorder was originally noted as occurring as epidemics, but it is now clear that it is an endemic illness with periodic epidemics. ${ }^{3}$ Despite exhaustive analysis no causal agent has been identified. ${ }^{3}$ Small outbreaks in Scotland in the early 1980s, however, suggested coxsackie B viruses as possible agents because increased serum antibody titres were detected in many patients. ${ }^{89}$ However, this is only indirect evidence as these viruses are common in the community. A more recent study disclosed chronic excretion of enterovirus in stools in $22 \%$ of a group of patients with the postviral fatigue syndrome. ${ }^{10}$ Other viruses - for example, varcicella-zoster virus, hepatitis B virus, and Epstein-Barr virus-have been implicated. ${ }^{3}$

A preliminary investigation to detect enterovirus specific RNA sequences in samples of muscle from patients with the postviral fatigue syndrome disclosed that a fifth of the 96 cases tested were positive with a nucleic acid hybridisation technique." With the advent of the highly sensitive polymerase chain reaction it is possible to examine for low copy numbers of nucleic acid sequences in cells and tissues. ${ }^{12}$ The technique is at least one thousandfold more sensitive than previous hybridisation protocols, and background hybridisation associated with enteroviral complementary DNA probes is eliminated. We used the polymerase chain reaction to search for the presence of enteroviral RNA sequences in a well characterised group of patients with the postviral fatigue syndrome. 
Patients and methods

PATIENT SAMPLE

We studied 60 patients with the postviral fatigue syndrome consecutively admitted during 18 months to the Institute of Neurological Sciences. There were 27 men (age range $15-56$ years, mean 34.6 years) and 33 women (age range 16-58 years, mean 39.6 years). The criteria for selection were that they all had severe fatigue starting after an acute, apparently viral, episode which had lasted more than a year and was severe enough to reduce their daily activity to less than half of its previous level. In addition, they had already undergone extensive investigation to exclude the many other conditions which enter into the differential diagnosis of the syndrome.

Their symptoms were overwhelming fatigue made worse by exercise, myalgia and depression, and poor concentration and short term memory. A febrile illness with upper respiratory or gastrointestinal symptoms, of such severity that the patient was confined to bed for several days, was the initial event in all patients. At the same time, excessive somnolence had started and lasted for several months with, in 10 patients, complete reversal of normal sleep pattern for more than one year. The severity of the disease fluctuated, with occasiona days or short periods of remission. Thirty six patients had symptoms of depression with a distinct diurnal variation. Twenty had had palpitations and pains in the chest, of whom 10 had been referred to a cardiologist; 20 had severe unsteadiness at the onset of the disease; 10 felt hot and cold inappropriately or sweated excessively. In 10 patients the initial clinical diagnosis was infectious mononucleosis.

Before their illness all 60 patients had considered themselves to be in good physical health. They all had previously satisfactory work and social records. Thirty five were professionals: nurses, doctors, solicitors, and bank or insurance managers; 15 were semiskilled or unskilled; five were housewives; and five were students.

All patients were admitted to hospital. A detailed physical and neurological assessment was carried out. Routine laboratory investigations performed included urine analysis; complete blood count; measurement of erythrocyte sedimentation rate; serum electrolyte estimations; liver function tests; creatine kinase estimation; thyroid function tests; chest radiography; electrocardiography; and determinations of serum immunoglobulin concentrations, complement components, antinuclear antibody and rheumatoid factor and peripheral blood $\mathrm{T}$ and $\mathrm{B}$ lymphocyte subpopulations. A serological screen was carried ou for coxsackieviruses B1-5 by neutralisation and for influenza A and B viruses, adenovirus, mycoplasma, $\mathrm{Q}$ fever, psittacosis, cytomegalovirus, respiratory syncytial virus, herpes simplex, varicella-zoster, mumps, and measles infections by complement fixation. Epstein-Barr virus specific IgM was detected by immunofluorescence. Electromyography was performed in 35 patients. Lumbar puncture, testing of visual evoked responses, computed tomography, and nuclear imaging of muscle were done in five patients in whom an alternative diagnosis had been proposed. No patient was admitted to the study if he or she had any other condition which might explain some of the findings. Needle muscle biopsies of the vastus lateralis were carried out in all patients.

\section{CONTROL SAMPLE}

We examined 13 men (mean age 56.0 years) and 28 women (mean age $48 \cdot 2$ years) from the same catchment area as the patients, who were selected during the same period. Their serological data were similar (see discussion). None had any evidence of muscular problems or complained of undue fatigue. They were all undergoing routine surgical procedures, and $1.5 \mathrm{~mm}^{3}$ samples of skeletal muscle were taken from the operative site at the time of operation. The clinical diagnoses or procedures were carcinoma of the breast (15 patients), coronary artery bypass (six), femoral artery bypass (three), thyroid lobectomy (three), cholecystectomy (two), partial gastrectomy (two), partial colectomy (four), carotid endarterectomy (one), repair of abdominal hernia (two), pinning of fractured hip (one), benign lump in breast (two).

\section{MUSCLE BIOPSIES}

The patients complained of generalised fatigue but, for convenience, samples were taken from the right or left vastus lateralis. Three cores of skeletal muscle were obtained with the modified UCH needle, under local anaesthesia. One and a half cores were snap frozen in cooled Arcton or liquid nitrogen for storage and examination by histochemical and routine staining, and one half core was fixed in $2 \%$ gluteraldehyde for ultrastructural analysis. ${ }^{13}$ The core for examination by the polymerase chain reaction was retrieved from the cannula with a sterile needle, placed in a sterile container, snap frozen, and stored in liquid nitrogen until required.

\section{POLYMERASE CHAIN REACTION}

RNA was prepared from a $1.5 \mathrm{~mm}^{3}$ muscle biopsy specimen or $1 \times 10^{7}$ tissue culture cells by the acid guanidium-phenol-chloroform method. ${ }^{14}$ The analysis of RNA was performed as previously described. ${ }^{15}$ Briefly, RNA was copied into complementary DNA (cDNA) with $M-M L V$ reverse transcriptase using an antisense primer (ABL2 or EP4). The polymerase chain reaction was then performed with a mixture of sense and antisense primers ABL1/ABL2 (human) or EP1/EP4 (viral). These primer pairs give rise to amplified bands of 218 base pairs ${ }^{15}$ and 414 basic pairs respectively. The Ableson tyrosine kinase gene primers (ABL1/ABL2) were used as they give rise to a positive band in all human RNA samples and therefore control for the quality of RNA and successful amplification, especially if there is no detectable amplification of enteroviral products. Only those samples that gave a positive $A B L$ gene band were used for analysis of RNA by the enteroviral polymerase chain reaction. Great care was taken to avoid contamination with extraneous RNA during amplification. Dedicated pipettes were used, and samples were processed only in batches of 10. Calf thymus DNA, normal human muscle RNA, Vero or Hep 2 cell RNA, and a reaction tube containing no nucleic acid were included as negative controls.

A programmable heating block (Techne Cambridge) was used for the amplification. This device was set to give 1 minute at $94^{\circ} \mathrm{C}, 1$ minute at $55^{\circ} \mathrm{C}$, and 1.5 minutes at $72^{\circ} \mathrm{C}$. Thirty five cycles of amplification were carried out. The products were electrophoresed through a $2 \%$ agarose gel, stained with ethidium bromide, and visualised under ultraviolet. The gels were then immobilised on a nylon membrane and hybridised with internal oligonucleotide EP2 labelled with either phosphorus-32 or digoxigenin (Boehringer). Alternatively, polymerase chain reaction products were slot-blotted (Bio-Rad Bio-Dot SF apparatus) directly on to nylon (GeneScreen Plus) and similarly hybridised. Filters were washed at a relatively low stringency to retain any mismatched hybrids with fivefold strength salt sodium phosphate EDTA (SSPE), and $0 \cdot 1 \%$ sodium dodecyl sulphate for 30 minutes at room temperature and single strength SSPE and, $0 \cdot 1 \%$ sodium dodecyl sulphate for 30 minutes at $60^{\circ} \mathrm{C}$. After washing, the filters were either processed for the digoxigenin colour reaction according to the manu- 
facturers' protocol or the blots were exposed to Kodak XAR5 film at $-70^{\circ} \mathrm{C}$ using intensifying screens.

We chose polymerase chain reaction primers from the conserved $5^{\prime}$ non-translated region in order to anneal to and prime complementary DNA from a wide range of enteroviral types. The oligonucleotide sequences were as follows:

ABL1: 5' CAG CGG CCA GTA GCA TCT GAC TT 3'; ABL2: 5' TGT GAT TAT AGC CTA AGA CCC GGA G 3'; EP1: 5' CGG TAC CTT TGT GCG CCT GT 3' (base pairs 64 to 83); EP2: 5' TAT TGA GCT AGT TGG TAG TCC TCC GG $3^{\prime}$ (base pairs 430 to 455, internal probe); EP4: 5' TTA GGA TTA GCC GCA TTC AG 3' (base pairs 459 to 478 ).

\section{Results}

The routine laboratory investigations disclosed no significant abnormalities and the samples of muscle showed no evidence of inflammation or necrosis. Only mild to moderate, non-specific atrophy of type 2 fibres was detectable in the biopsy specimens, in keeping with a chronic illness. Of the 60 patients, 12 had neutralising titres of $\geqslant 256$ to one of the coxsackieviruses B1-5 (six were positive for enterovirus RNA


FIG 1-Top: Amplification products of range of host cells and enteroviral RNAs produced with enteroviral primers EPI and EP4 and stained with ethidium bromide. Lane 1 coxsackievirus A16; lane 2 coxsackievirus A21; lanes 3-8 coxsackieviruses B1-6; lane 9 MRC5 cells; lane $10 \mathrm{Hep} 2$ cells; lane 11 normal human muscle; lane 12 Vero cells; lane $M 123$ base pair ladder (base raw ladder). Bottom: Southern blot of same gel hybridised with digoxygenin labelled olignonucleotide probe EP2

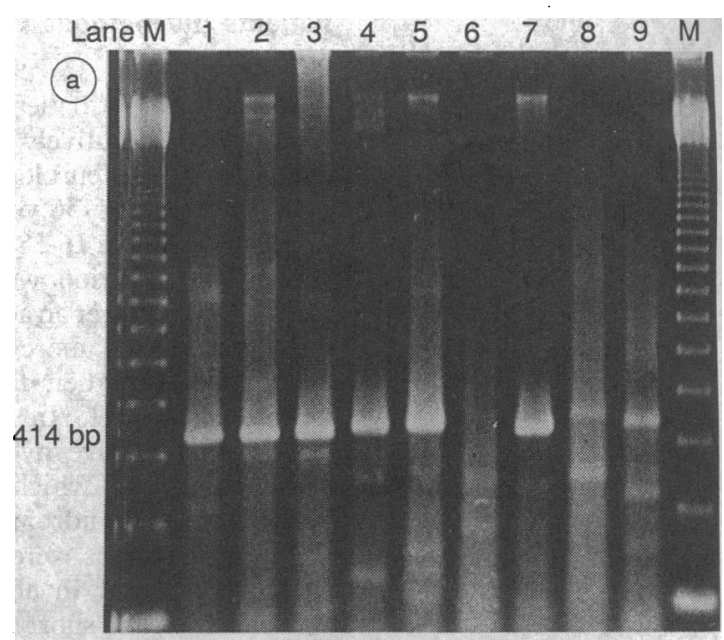

FIG 2-Top: Amplification products of enteroviral RNAs produced with enteroviral primers EPI and EP4 and stained with ethidium bromide. Lanes 1-3 polioviruses 1-3; lanes 4-7, echoviruses $9,11,22$, 30 respectively; lane 8 enterovirus 68; lane 9, enterovirus 70; lane $M 123$ base raw ladder. Bottom: Southern blot of same gel hybridised with digoxygenin labelled oligonucleotide probe EP2

with the polymerase chain reaction and six were negative), three were positive for Epstein-Barr virus specific IgM (two positive and one negative), and there were no other significant findings. Of the 41 controls, six had neutralising titres of $\geqslant 256$ to one of the coxsackieviruses B1-5 (all negative with the polymerase chain reaction), one was positive for EpsteinBarr virus specific IgM (negative), and three had complement fixing antibody to cytomegalovirus titres of $\geqslant 256$ (all negative). In summary, $25 \%$ of the patients and $24.4 \%$ of the controls had significant serological findings.

To assess the feasibility of applying the polymerase chain reaction technique to detecting enteroviral RNA in muscle it was first necessary to show that a sequence common to various enteroviral types could be amplified. Figure 1 shows that the enteroviral polymerase chain reaction primers EP1 and EP4 amplified a specific 414 base pair band from cells infected with coxsackieviruses A and B (lanes 1-8) but not from the uninfected cell lines or normal human muscle (lanes 9-12). The presence of enteroviral sequences in the polymerase chain reaction bands was confirmed by Southern blot analysis and hybridisation with the internal oligonucleotide probe EP2 (fig 1).

The primers EP1 and EP4 also amplified a common sequence from poliovirus, echovirus, and higher enterovirus types (fig 2). Figure 2 confirms the viral sequence. Echovirus 22 (fig 2a, lane 6) did not give rise to the expected 414 base pair band, suggesting that this virus stands apart from others in the same group. ${ }^{17}$ Coxsackievirus A21, poliovirus 2, and echovirus 30 
hybridised weakly with the internal probe, although they gave rise to very strong positive bands visible by ethidium bromide staining (fig 1b). Enterovirus 68, which gave rise to a band slightly larger than 414 base pairs (fig 2a) did not hybridise with probe EP2.

Though there is sequence variation within the enteroviral group at the $5^{\prime}$ end, there is sufficient conservation to regard the primers selected as being of broad specificity for a wide range of enterovirus. Amplification of the uninfected cell controls; normal human muscle, and measles virus (not shown) was consistently negative, showing the specificity of the enteroviral primers.

To assess the sensitivity of the polymerase chain reaction technique $5 \mu \mathrm{g}$ total RNA from coxsackievirus B3 infected HEp 2 cells was serially diluted with RNA from uninfected cells. The cells had been washed several times with phosphate buffered saline during harvest to remove any free virus particles from the culture medium. Dilutions from 1 in 10 to 1 in 10 were made. A positive band was visible by ethidium bromide staining at the 1 in $10^{4}$ dilution, and after hybridisation with an internal probe a positive signal was visible in autoradiographs for dilutions down to 1 in $10^{6}$ (not shown). RNA at a dilution of 1 in $10^{3}$

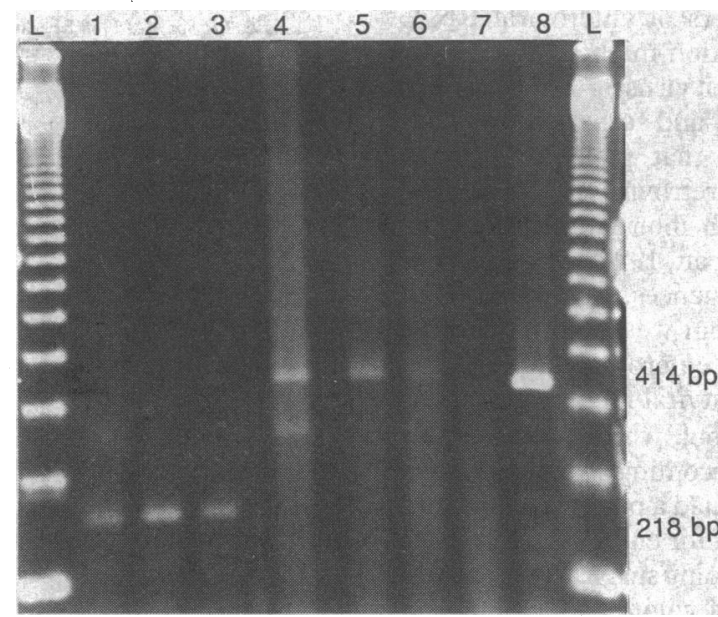

FIG 3-Amplification products of RNA isolated from muscle biopsy specimens of three patients with postviral fatigue syndrome stained with ethidium bromide. Lanes 1-3 RNA amplified with $A B L$ gene primers $A B L 1$ and $A B L 2$; lanes 4-6 RNA amplified with enteroviral primers EPI and EP4; lane 7 uninfected Vero cell negative control; lane 8,1 in $10^{3}$ dilution coxsackievirus $B 3$ infected Vero cell positive control; lane L 123 base pair ladder

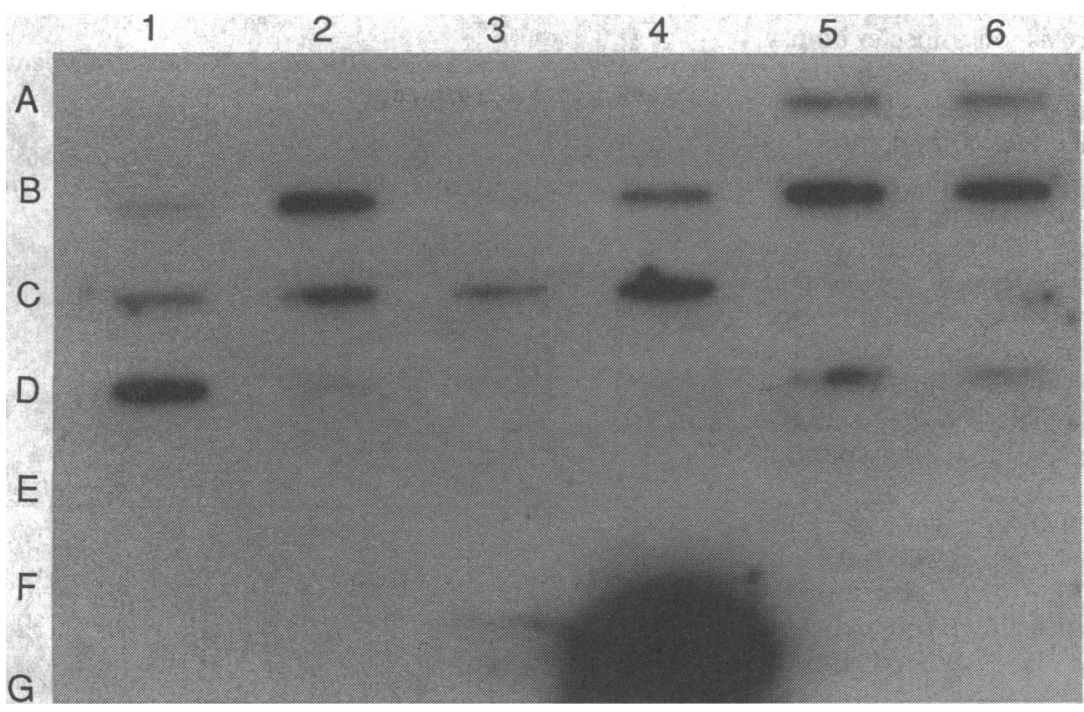

FIG 4-Detection of enteroviral amplification products from muscle biopsy specimens from patients with postviral fatigue syndrome by slot-blot assay and hybridisation with internal ${ }^{32} P$-labelled oligonucleotide probe EP2. Slots Al-6, B1-6, C1-6, and D1-6 muscle biopsy specimens; slot G1 calf thymus DNA control; slot $G 2$ uninfected Vero cell control; slot $G 4,1$ in $10^{3}$ dilution coxsackievirus B3 infected Vero cell control; slot $G 6$ polymerase chain reaction with no nucleic acid present from coxsackievirus B3 infected/uninfected cells was routinely used as the positive control in each experiment.

Figure 3 shows examples of ABL gene and enteroviral polymerase chain reaction products from muscle biopsy specimens from three patients with the postviral fatigue syndrome. The 218 base pair ABL gene band was observed in all samples by gel electrophoresis and ethidium bromide staining. A visible 414 base pair enteroviral band from $20 \mu \mathrm{l}$ polymerase chain reaction product was present in $16 \%$ of biopsy specimens from patients with postviral fatigue syndrome. To increase the sensitivity $60 \mu \mathrm{l}$ of polymerase chain reaction product was slot-blotted on to nylon and hybridised with ${ }^{32} \mathrm{P}$-labelled probe EP2. Figure 4 shows an example of a typical slot-blot experiment. Most positive samples could be readily detected in the autoradiographs after a 16 hour exposure. Autoradiographs were re-exposed for 10 days to ensure that no weak positive signals were missed. It is important to note the difference in signal between the 1 in $10^{3}$ dilution of the infected/uninfected cell control (slot G4) and the positive signals in the samples of patients' muscle, suggesting that either the number of viral copies per cell is very low or very few cells were infected.

Of the 60 patients with the postviral fatigue syndrome, $32(53 \%)$ were positive for enteroviral RNA sequences in muscle after polymerase chain reaction amplification and hybridisation with EP2, and of the 41 controls, six (15\%) were positive. Statistical analysis with the $\chi^{2}$ test shows that these results are highly significant $\left(p<0.001,\left(\alpha=0.05, \mathrm{df}=1, \chi^{2}\right.\right.$ with correction for continuity $=13.94$; therefore $p<0.001)$ ). The relative odds ratio of the postviral fatigue syndrome in patients with enteroviral infection was 6.7 $(32 \times 35 / 28 \times 6) \cdot(95 \%$ confidence interval $2 \cdot 4$ to $18 \cdot 2)$. Enteroviral sequences were detected in 12 of the 27 male and 20 of the 33 female patients. There was no correlation between duration of disease, patient, and age and positivity by polymerase chain reaction.

\section{Discussion}

In this study we investigated a large group of patients with the postviral fatigue syndrome for the presence of persistent enterovirus infection in muscle. The criteria we used are similar to those proposed as a working case definition of the chronic fatigue syndrome,' but we purposely avoided this term because it is so non-specific and depends largely on the exclusion of a vast number of different syndromes.

The control sample was taken from the same catchment area and was studied over the same period as the patients. It is very likely that the groups had the same exposure to common viruses as serological tests disclosed similar results in the two: $25 \%$ of patients and $24 \cdot 1 \%$ of controls had increased antibody titres to coxsackieviruses, Epstein-Barr virus, or cytomegalovirus. None of the controls had any muscular problems. It was not considered ethical or practicable to perform biopsy in a large group of normal healthy subjects, so that the control sample consisted of patients undergoing surgical procedures, from whom a minute fragment of muscle could be obtained at operation. This accounts for the slightly different age and sex structure of this group.

The epidemiology of the postviral fatigue syndrome, its incubation period, and the abrupt onset of a feverish illness all suggest that a viral infection is responsible. However, no virus has been found to be consistently associated. Serological analysis for viral antigens has been unhelpful, ${ }^{3}$ as we confirmed in a recent study. ${ }^{16}$

In this study there was no correlation between raised titres to coxsackieviruses B1-5 and the detection of enterovirus specific RNA in muscle biopsy specimens. 
In view of the broad specificity of the polymerase chain reaction technique used for a wide range of enteroviruses, this is not surprising. In both patient and control groups three quarters of the subjects had no significant serological findings. These results are in keeping with those in our larger, serological study. ${ }^{16}$

Several groups have presented data on polymerase chain reaction of enterovirus. ${ }^{118}$ We used this technique to search for enteroviral RNA in muscle because its exquisite sensitivity enables the detection of a few copies of enteroviral sequences in the cell. Previously, with nucleic acid hybridisation, a fifth of patients with the postviral fatigue syndrome were positive for enterovirus specific sequences. ${ }^{11}$ We found that $53 \%$ of 60 patients with the syndrome had specific enteroviral RNA, suggesting persistent infection in the muscle. These results are statistically significant; the relative odds ratio for the postviral fatigue syndrome in patients with enteroviral infection is 6.7 (95\% confidence interval $2 \cdot 4$ to $18 \cdot 2$ ).

With regard to the $47 \%$ of patients with negative results, there are several possible explanations. The viral infection in the muscle may be focal; the EP2 probe we used may be too type-specific (other probes are now being investigated), or the polymerase chain reaction itself may still not be sensitive enough to detect very low copy numbers of enteroviral RNA. Also, the same clinical condition might be caused by infection of muscle with other viruses. Enteroviruses may be opportunistic. We and others now have preliminary data to suggest that patients with the syndrome may also harbour a retrovirus (E De Freitas, et al, abstract of the eleventh international congress of neuropathology, Kyoto, Japan, 1990) or are expressing endogenous retroviral sequences.

We emphasise that at present we do not regard the polymerase chain reaction for enteroviral sequences as a "diagnostic test" for the postviral fatigue syndrome. At this stage it is a research tool, which in due course may lead to a diagnostic test becoming available. In this study no healthy young adult had a positive result with the polymerase chain reaction for enterovirus. Among our 41 control patients undergoing surgical procedures, six had a positive result, all of whom had a malignant tumour (five carcinoma of the breast and one carcinoma of the colon). The significance of this finding is at present unknown

A major difficulty in postulating a viral cause for the postviral fatigue syndrome has been the lack of any morphological evidence of cell injury or inflammation. None of our patients had increased serum creatine kinase activity or cell necrosis on muscle biopsy. Oldstone showed clearly in animal models, however, that viruses may infect tissue persistently without producing any morphological effect, although they do interfere, partially or completely, with the specialised function of the host cell. ${ }^{19}$ Viral persistence seems to be particularly likely if the agent infects longlived cells such as lymphocytes or cells in the nervous system. Enteroviruses are known to produce continuing infection in humans, ${ }^{20}$ and recent work on a very small sample of patients with the postviral fatigue syndrome suggested that there is an unusual ratio of sense to antisense copies of the viral RNA, perhaps accounting for its persistence. ${ }^{21}$

The features of the postviral fatigue syndrome point to involvement of the nervous system as well as muscle. It is tempting to speculate that virus remains here also, perhaps interfering with cellular production of neurotransmitters; it may also be associated with the depression.

On the basis of the results of this study we postulate that there is persistent enteroviral infection in the muscle of some patients with the postviral fatigue syndrome and that this interferes with cell metabolism and is causally related to the fatigue.

The main support for this work was provided by the Barclay Trust. Additional help was given by the Myalgic Encephalomyelitis Association, the Scottish Motor Neurone Disease Association, and the Scottish Hospitals Endowments

Research Trust.

1 Acheson ED. The clinical syndrome variously called benign myalgic encephalomyelitis, Iceland disease and epidemic neuromyasthenia. Am $\mathcal{J}$ Med 1959;26: 569-95

2 Henderson DA, Shelokov A. Epidemic neuromyasthenia: clinical syndrome? N Engl f Med 1959;260:757-64.

3 Behan PO, Behan WMH. Postviral fatigue syndrome. Crit Rev Neurobiol 1988;4:157-78.

4 Jamal GA, Hansen S. Post-viral fatigue syndrome: evidence for underlying organic disturbance in the muscle fibre. Eur Neurol 1989;29:272-6.

5 Arnold DL, Radda GK, Bore PJ, Styles P, Taylor DJ. Excessive intracellular acidosis of skeletal muscle on exercise in a patient with postviral exhaustion/ fatigue syndrome. Lancet 1984;i:1367-9.

6 Behan PO, Behan WMH, Bell EJ. The postviral fatigue syndrome-an analysis of the findings in 50 cases. F Infect 1985;10:211-22.

7 Holmes GP, Kaplan JE, Gantz NM, et al. Chronic fatigue syndrome: a working case definition. Ann Intern Med 1988;108:387-9.

8 Fegan KG, Behan PO, Bell EJ. Myalgic encephalomyelitis-report of an epidemic. $7 R$ Coll Gen Pract 1983;33:335-7.

9 Calder BD, Warnock PJ, McCartney RA, Bell EJ. Coxsackie B viruses and the post-viral fatigue syndrome: a prospective study in general practice. $f R$ Coll Gen Pract 1987;37:11-14.

10 Yousef GE, Bell EJ, Mann GF, et al. Chronic enterovirus infection in patients with post-viral fatigue syndrome. Lancet 1988 ; i: 146-50

11 Archard LC, Bowles NE, Behan PO, Bell EJ, Doyle D. Postviral fatigue syndrome: persistence of enterovirus RNA in muscle and elevated creatine kinase. F R Soc Med 1988;81:326-9.

12 Eisenstein BI. The polymerase chain reaction. $N$ Engl f Med 1990;322:178-83. 3 Dubowitz V. Muscle biopsy. A practical approach. 2nd ed. London: Baillière Tindall, 1985:3-40.

14 Chomczynski P, Sacchi N. Single step method of RNA isolation by acid guanidium thiocyanate phenol chloroform extraction. Anal Biochem 1987; 162:156-9.

15 Hermans A, Gow J, Selleri L, et al. bcr-abl oncogene activation in Philadelphia chromosome positive acute lymphoblastic leukemia. Leukemia 1988;2: 628-33.

16 Miller NA, Carmichael HA, Calder BD, et al. Antibody to coxsackie B virus in diagnosing postviral fatigue syndrome. $B M \mathcal{F} 1991 ; 302: 140-3$.

17 Chapman NM, Tracy S, Guantt CJ, Fortmueller G. Molecular detection and identification of enteroviruses using enzymatic amplification and nucleic acid hybridization. F Clin Microbiol 1990;28:843-50.

18 Hyypia T, Auvinen P, Maaronen M. Polymerase chain reaction for human picornaviruses. F Gen Virol 1989;70:3261-8.

19 Oldstone MBA. Viruses can cause disease in the absence of morphological evidence of cell injury: implication for uncovering new diseases in the future. F Infect Dis 1989;159:384-9.

20 Wilfert CM, Buckley RH, Mohanakumar T, et al. Persistent and fatal centralnervous-system echovirus infections in patients with agammaglobulinemia. N Engl f Med 1977;296:1485-9.

21 Cunningham L, Bowles NE, Lane RJM, Dubowitz V, Archard LC Persistence of enteroviral RNA in chronic fatigue syndrome is associated with the abnormal production of equal amounts of positive and negative strands of enteroviral RNA. $\mathcal{F}$ Gen Virol 1990;71:1399-402.

(Accepted 6 February 1991)

\section{Correction}

How well can radiographers triage $x$ ray films in accident and emergency departments?

The table in this paper by Dr I G H Renwick et al (9 March, p 568) was incompletely printed. It should read:

Number (percentage) of $x$ ray films identified by radiographers and verified by radiologists in accident and emergency department

\begin{tabular}{|c|c|c|c|c|c|c|}
\hline & \multicolumn{2}{|c|}{ Normal films } & \multicolumn{2}{|c|}{ Abnormal films } & \multirow[b]{2}{*}{$\begin{array}{l}\text { Further } \\
\text { advice } \\
\text { required }\end{array}$} & \\
\hline & $\begin{array}{l}\text { No of } \\
\text { correct } \\
\text { results }\end{array}$ & $\begin{array}{l}\text { No of false } \\
\text { positive } \\
\text { results } \\
\text { (\% of normal } \\
\text { films) }\end{array}$ & $\begin{array}{l}\text { No of } \\
\text { correct } \\
\text { results }\end{array}$ & $\begin{array}{l}\text { No of false } \\
\text { negative } \\
\text { results } \\
\text { (\% of } \\
\text { abnormal } \\
\text { films) }\end{array}$ & & \\
\hline Facial bones & 67 & $8(11)$ & 21 & $5(19)$ & 6 & 107 \\
\hline Skull & 198 & $14(7)$ & 6 & $2(25)$ & 10 & 230 \\
\hline Thoracolumbar spine & 97 & $13(12)$ & 54 & & 5 & 169 \\
\hline Cervical spine & 103 & $7(6)$ & 31 & & 12 & 153 \\
\hline Long bones & 477 & $12(2)$ & 298 & $5(2)$ & 19 & 811 \\
\hline Ankles & 153 & $7(4)$ & 83 & $15(15)$ & 9 & 267 \\
\hline Hands and feet & 633 & $59(9)$ & 256 & $37(13)$ & & 985 \\
\hline Chest & 477 & $49(9)$ & 347 & $92(21)$ & 54 & 1019 \\
\hline Abdomen & 42 & $3(7)$ & 10 & $5(33)$ & 6 & 66 \\
\hline Soft tissues or sinuses & 136 & $17(11)$ & 4 & $26(87)$ & 4 & 187 \\
\hline Total & 2383 & $189(7)$ & 1110 & $187(14)$ & 125 & 3994 \\
\hline
\end{tabular}

